\section{Self-inflicted penetrating injury to head with complete preservation of consciousness in a psychotic patient}

Sir,

Penetrating injury to the cranio-facial region is a common occurrence. Most cases are due to motor vehicle accidents, fall from height or physical assault cases. Variable neurological deficits with or without loss of consciousness are the most common presentations. We report an interesting case of a self-driven iron rod into the head with complete preservation of consciousness and no neurological deficit in a patient suffering from delusional disorder. We could not find such presentation in the literature.

A 19-year-old female presented to us with an iron rod penetrating into the center of the lower part of forehead in the glabellar region. Her history revealed a very strange incidence in which she held the iron rod by her both hands and hammered the head forcefully against it. She was fully conscious with no focal neurological signs. The patient was completely apathetic to the pain of such trauma [Figure 1]. Plain X-ray of skull showed about 5 inches of iron rod penetrating through the anterior skull base into the cranial cavity [Figure 2]. CT scan showed the same picture with no parenchymal damage or extra-axial blood collection [Figure 3]. A wide craniotomy centering on the entry point of the

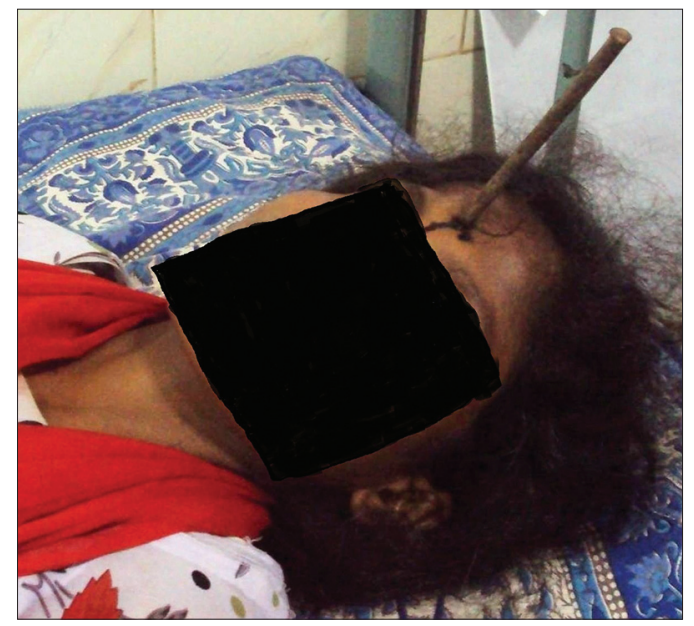

Figure 1: Fully conscious patient with the long iron rod driven into her forehead rod was made. The rod was found to lacerate the dura and extending between it and the orbital surface of the frontal lobe. There was no damage to the frontal lobe or critical neurovascular structures in the anterior cranial fossa. On retracting the frontal lobe, the rod was found to extend below the optic chiasm with its tip lying in the pre-pontine cistern just short of the brainstem. It was abutting the pituitary stalk in the suprasellar cistern. The rod was carefully removed by pushing from the inside rather than pulling it out [Figure 4]. Postoperatively the patient recovered normally with no CSF leak, diabetes incipidus or any other neurological deficits [Figure 5]. She was sent to a psychiatrist and diagnosed as a case of schizophrenia with acute delusional disorder. After thorough psychiatric evaluation she was found having delusions with voice commanding her to push the iron rod into her head. She believed that the voices were coming directly from the almighty. Interestingly, these voices were directing her to do that thing so that she could be blessed with great fortune and wealth. This could remove her misery of poverty. Hence, this was not an act of suicidal intent rather an impulsive attempt under the delusional influence to please God. She chose this method of self-torturing probably because the iron rod was easily available as she belonged to a family of construction worker. She was discharged on antipsychotic drugs. After 9-month follow-up the patient was showing gross improvement in her psychotic behavior with no further similar impulsive episodes, particularly under voice command.

Self-inflicted cranio-facial penetrating injuries are rare and few such cases have been reported in the literature. ${ }^{[1-5]}$ Almost all these cases are due to psychological diseases on suicidal intent. The craniofacial region is protected by underlying strong skull and facial bone and needs a lot of energy and power which is difficult to be inflicted by self. Again as this is region richly supplied by nerves, this makes such injuries extremely painful. All these

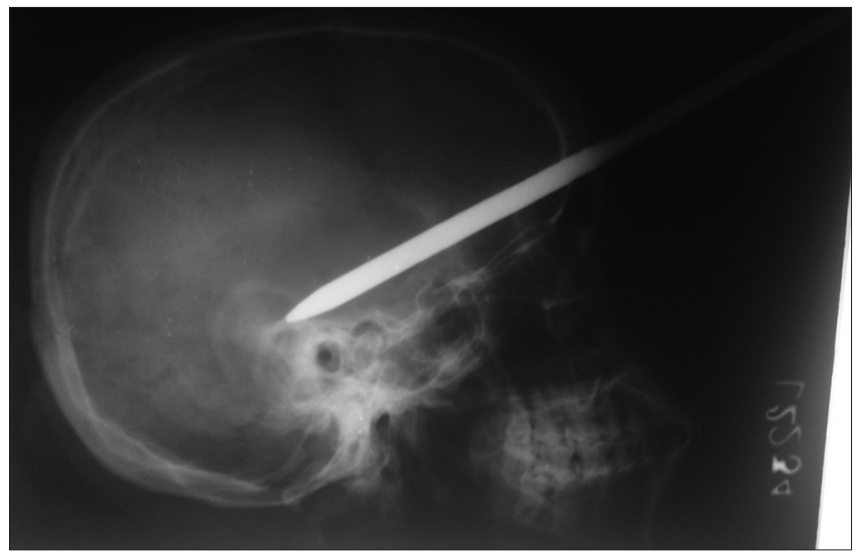

Figure 2: Skull lateral view X-ray showing the path of the rod 


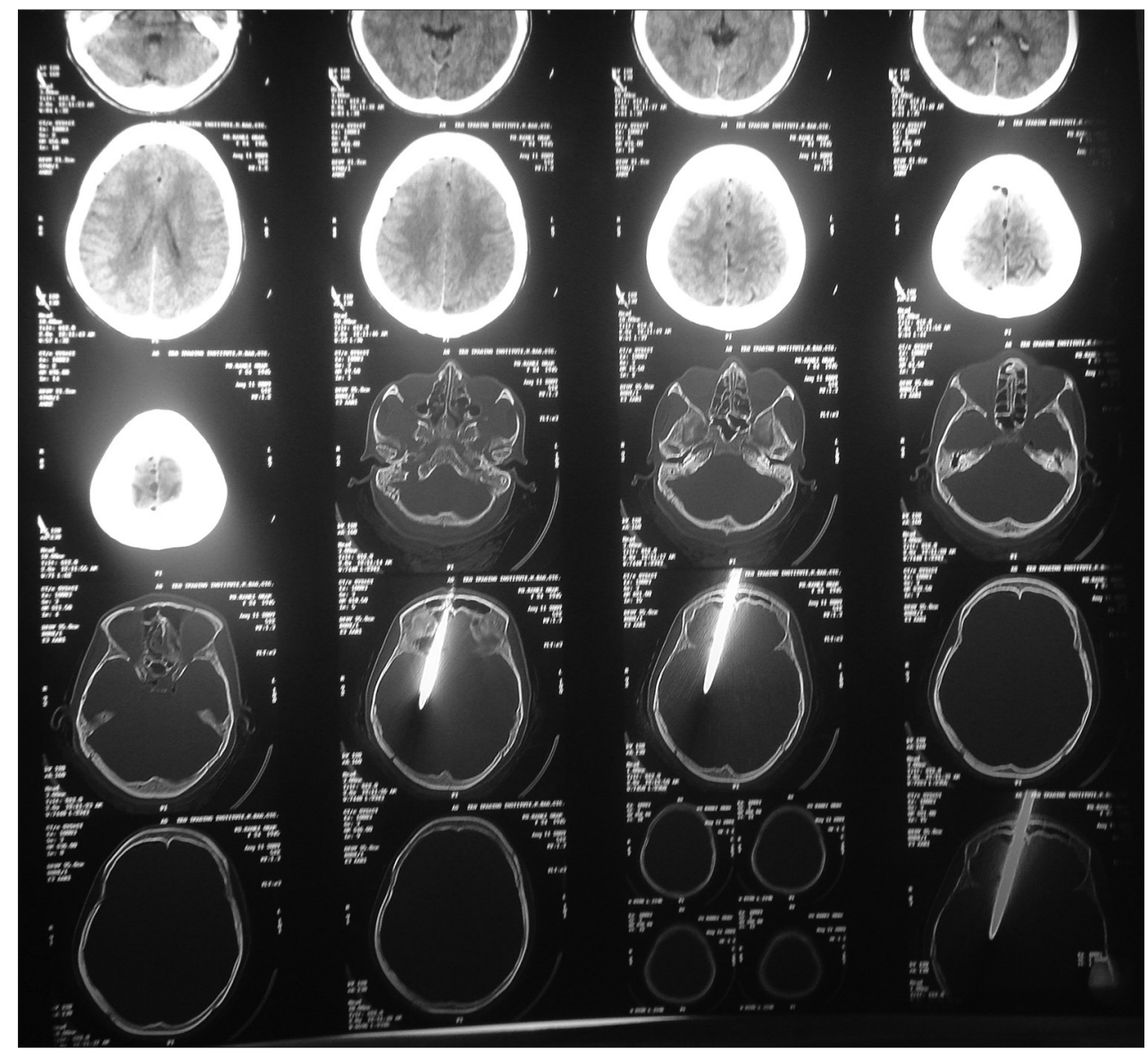

Figure 3: CT scan showing no parenchymal damage or extraaxial collection

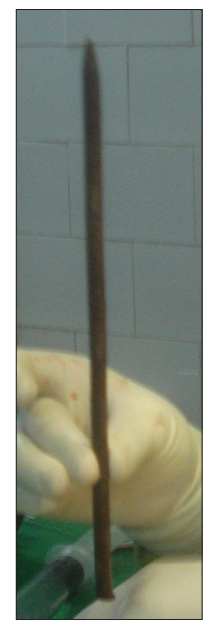

Figure 4: The removed iron rod

facts make this act almost impossible for a normal individual. However, the psychotic patients as in this present case who are under the influence of certain commands directing them to do certain specific acts have strong impulsive behavior, no insight, and complete apathy to pain to execute difficult manoeuvres so as to inflict such injuries on themselves. Psychologically

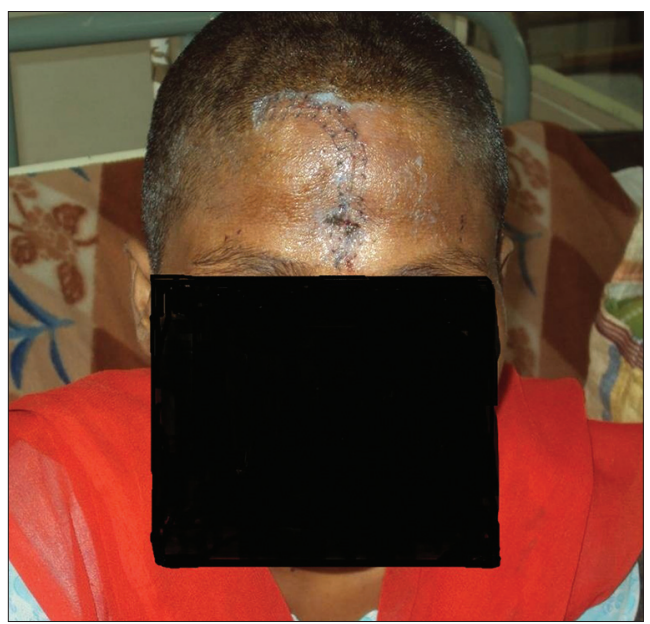

Figure 5: Postoperative picture showing the scar site

disordered patients have the tendency to self-harm repeatedly. ${ }^{[1]}$

Our case was exclusive in that the patient was completely conscious in spite of a long iron rod coursing through the anterior cranial fossa. This was possible because of the trajectory of the rod was 
between brain and the dura without damaging the former or any other vessels in the subarachnoid or subdural plane. Karabatsou et al., reported a similar case where the wire was penetrated into the right side cerebral hemisphere after creating a hole in the skull by power drill by a psychotic person. ${ }^{[2]}$ Green et al. reported a penetrating ballpoint pen through right medial canthus and intracranial compartment who developed a cavernous sinus syndrome and a traumatic dissection of the cavernous portion of the carotid artery. ${ }^{[3]}$ The schizophrenic patient reported by Shenoy et al. developed left side hemiparesis. ${ }^{[4]}$ Fortunately in our case both the brain and critical vascular structures escaped damage resulting in complete preservation of consciousness with no neurological deficits. Wide craniotomy, careful retraction, meticulous method of pushing from inside rather than pulling it directly resulted in safe removal of the iron rod and prevented development of any postoperative complications.

\section{Ashis Patnaik, Sudhansu Sekhar Mishra ${ }^{1}$ \\ Department of Trauma and Emergency, All India Institute of Medical Sciences (AlIMS), Bhubaneswar, ${ }^{1}$ Neurosurgery, SCB Medical College and Hospital, Cuttack, Odisha, India \\ Address for correspondence: Dr. Ashis Patnaik, Department of Trauma and Emergency, All India Institute of Medical Sciences (AllMS), Bhubaneswar, Odisha, India. E-mail:dr_ash007@yahoo.co.in}

\section{References}

1. Musa BS, Simpson BA, Hatfield RH. Recurrent self-inflicted craniocerebral injury: Case report and review of the literature. Br J Neurosurg 1997;11:564-9.

2. Karabatsou K, Kandasamy J, Rainov NG. Self-inflicted penetrating head injury in a patient with manic-depressive disorder. Am J Forensic Med Pathol 2005;26:174-6.

3. Greene KA, Dickman CA, Smith KA, Kinder EJ, Zabramski JM. Self-inflicted orbital and intracranial injury with a retained foreign body, associated with psychotic depression: Case report and review. Surg Neurol 1993;40:499-503.

4. Shenoy SN, Raja A. Unusual self-inflicted penetrating craniocerebral injury by a nail. Neurol India 2003;51:411-3.

5. Litvack ZN, Hunt MA, Weinstein JS, West GA. Self-inflicted nail-gun injury with 12 cranial penetrations and associated cerebral trauma. Case report and review of the literature. J Neurosurg 2006;104:828-34.

\begin{tabular}{|l|l|}
\hline \multicolumn{2}{|c|}{ Access this article online } \\
\hline Quick Response Code: & Website: \\
\hline & www.ruralneuropractice.com \\
\cline { 2 - 3 } & \\
\hline & \\
\hline
\end{tabular}

